\title{
First trimester exposure to ambient gaseous air pollutants and risk of orofacial clefts: a case- control study in Changsha, China
}

\author{
Wen Jiang ${ }^{1}$, Wanqin Xie ${ }^{2}$, Bin Ni², Haiyan Zhou' ${ }^{1}$ Zhiyu Liu²* and Xingli $\mathrm{Li}^{\mathrm{i}^{*}}$
}

\begin{abstract}
Background: A growing body of studies have investigated the association between air pollution exposure during early pregnancy and the risk of orofacial clefts, but these studies put more emphasis on particulate matter and reported inconsistent results, while research on the independent effects of gaseous air pollutants on orofacial clefts has been quite inadequate, especially in China.
\end{abstract}

Methods: A case-control study was conducted in Changsha, China from 2015 to 2018. A total of 446 cases and 4460 controls were included in the study. Daily concentrations of $\mathrm{CO}, \mathrm{NO}_{2}, \mathrm{SO}_{2}, \mathrm{O}_{3}, \mathrm{PM}_{2.5}$ and $\mathrm{PM}_{10}$ during the first trimester of pregnancy were assigned to each subject using the nearest monitoring station method. Multivariate logistic regression models were applied to evaluate the associations of monthly average exposure to gaseous air pollutants with orofacial clefts and its subtypes before and after adjusting for particulate matter. Variance inflation factors (VIFs) were used to determine if the effects of gaseous air pollutants could be independent of particulate matter.

Results: Increase in $\mathrm{CO}, \mathrm{NO}_{2}$ and $\mathrm{SO}_{2}$ significantly increased the risk of cleft lip with or without cleft palate (CL/P) in all months during the first trimester of pregnancy, with aORs ranging from 1.39 to 1.48 , from 1.35 to 1.61 and from 1.22 to 1.35 , respectively. The risk of cleft palate only (CPO) increased with increasing $\mathrm{NO}_{2}$ exposure levels in the first trimester of pregnancy, with aORs ranging from 1.60 to 1.66. These effects sustained and even exacerbated after adjusting for particulate matter. No significant effect of $\mathrm{O}_{3}$ was observed.

Conclusions: Our study suggested that maternal exposure to $\mathrm{CO}, \mathrm{NO}_{2}$, and $\mathrm{SO}_{2}$ during the first trimester of pregnancy might contribute to the development of orofacial clefts, and the associations were potentially independent of particulate matter.

Keywords: Gaseous air pollution, Particulate matter, Orofacial clefts

\section{Introduction}

Orofacial clefts are common congenital malformations comprising a range of disorders affecting the lips and

*Correspondence: 315038356@qq.com; lixingli@csu.edu.cn

tWen Jiang and Wanqin Xie are co-first authors.

${ }^{1}$ Department of Epidemiology and Health Statistics, Xiangya School

of Public Health, Central South University, Xiangya Road, Kaifu District,

Changsha 410078, China

${ }^{2}$ Maternal and Child Health Care Hospital of Hunan Province, Changsha, China oral cavity. They are generally subdivided into two types according to distinct developmental origins from embryo: cleft palate only (CPO) and cleft lip with or without cleft palate $(\mathrm{CL} / \mathrm{P})$ [1]. The malformations occur in about 1.7 per 1000 live-born babies, which can increase morbidity and mortality of perinatal infants, impair social adaptive ability of the survivors, and impose financial burdens on the family involved and the society at large because of the relevant health care services required [2]. Both genetic components and environmental factors have been linked 
to the development of orofacial clefts. However, the etiology of the defects is not fully understood [3].

Animal studies have shown that pregnant mice suffering from higher levels of carbon monoxide (CO) and ozone $\left(\mathrm{O}_{3}\right)$ tended to give birth to more offspring with skeletal malformations $[4,5]$, which may be the consequence of oxidative stress, cell toxicity, and hemodynamics during organogenesis period [6]. These evidence and potential biological rationales have encouraged a growing body of epidemiological studies to assess possible associations of air pollutants exposure during early pregnancy with congenital anomalies, which include orofacial clefts [7-10]. However, most previous studies were conducted in developed countries, where the concentration levels of air pollution tend to be lower than those in developing countries. Besides, existing researches put more emphasis on particulate matter (PM), while attention given to toxic gaseous components of air pollutants, such as $\mathrm{CO}$, nitrogen dioxide $\left(\mathrm{NO}_{2}\right)$, sulfur dioxide $\left(\mathrm{SO}_{2}\right)$ and $\mathrm{O}_{3}$ has been limited, with positive associations found in some $[6,11]$ but null in others $[12,13]$. More importantly, air pollution consists of various solid particles and gases, and it is unclear whether the associations between gaseous air pollutants and orofacial clefts are independent or are or due to exposure to other air pollutants.

Over the past decades, China has achieved great economical development. Meanwhile, the largest developing country in the world has been confronted with increasing challenges in environmental protection [14], and the health effects of gaseous air pollutants, which originate from massive combustion of various fuels, are one of the greatest concerns. Based on our review of existing literature, however, only a few studies have explored the effects of exposure to gaseous air pollutants on orofacial clefts in China, but have reported inconsistent results [15-18]. Of these studies, two used single-pollutant model without adjustment for the coexisting pollutants, thus failed to isolate the independent role of gaseous air pollutants $[15,16]$. Besides, it has been proven that the concentration of air pollution varies greatly in different areas of China [19], which may lead to different health effects. Therefore, more studies on the associations between gaseous air pollutants exposure and orofacial clefts are needed, especially in areas of high incidence of birth defects without exact causes, such as Changsha, China [20].

In this study, we utilized maternal and child health monitoring data from Changsha, China during the 2015-2018 period to examine the independent effects of maternal gaseous air pollutants $\left(\mathrm{CO}, \mathrm{NO}_{2}, \mathrm{SO}_{2}\right.$ and
$\mathrm{O}_{3}$ ) exposure during early pregnancy on the risk of orofacial clefts.

\section{Methods \\ Study area}

Changsha is a subtropical city with a typical monsoon climate located in the middle and lower reaches of the Yangtze River, central China, where the climate characterized by hot and rainy in summer, mild and light rain in winter. Local season can be divided into warm (MayOctober) and cold (November to April) based on temperature variation. The annual average precipitation is approximately $1361.6 \mathrm{~mm}$, and the annual average temperature is $17.2{ }^{\circ} \mathrm{C}$. It is also the capital city and the economic and cultural central of Hunan Province. According to statistics, approximately 8.39 million people reside in a land area of $11,819.0 \mathrm{~km}^{2}$ in Changsha.

\section{Study population}

This is a case-control study. The cases and controls were enrolled from the hospital based birth defect monitoring (HBBDM) system of Hunan Province and the electronic medical records (EMR) system of Maternal and Child Health Care Hospital of Hunan Province, respectively. Details of the establishment and operation of the two systems were described elsewhere [20]. Briefly, we abstracted all records of orofacial clefts (including stillbirth, dead fetus and live birth) with maternal residence during early pregnancy in Changsha and estimated date of conception between 1 January 2015 and 31 December 2018 from HBBDM system $(n=589)$. For each motherinfant pair, we collected information regarding maternal age, residential address during early pregnancy, education level, gravidity, date of pregnancy termination, gestational weeks (weeks + days), health condition, infant sex and subtype classification of orofacial clefts. Cases were excluded if they met any of the following criteria: (1) mother-infant pair information mentioned above missing from the system $(n=20)$; (2) maternal illness conditions, including gestation weeks $<20$ or $>44$, gestational diabetes, a family history of orofacial clefts or a history of other illness during pregnancy [i.e. fever $\left(>38^{\circ} \mathrm{C}\right)$, infection or exposure to antibiotics] $(\mathrm{n}=18)$; (3) with simultaneous genetic anomalies other than orofacial clefts $(n=12)$. Specifically, given that the regional nature of the studied air pollutants concentrations are different from each other, which may contribute to unacceptable exposure misclassification for those air pollutants with larger spatial gradients when using individual exposure assessment method listed below, a maximum radius of $25 \mathrm{~km}$ from the nearest monitoring station was selected as threshold to include cases following a previous study [21] (93 cases 
excluded). At the same time, 60,000 records of live-born infants without any congenital anomalies within the same range of estimated date of conception and maternal residences were randomly selected from the EMR system, followed by an exclusion process using the same criteria for cases. After that, remaining mother-infant pairs from the EMR system were matched 1:10 to cases by year of conception as controls. Date of conception was estimated using the termination date of pregnancy minus gestational age (week + day) for each mother.

\section{Classification of orofacial clefts}

Cases of orofacial clefts were diagnosed according to the International Classification of Diseases-10 (ICD-10) codes, which including cleft palate only (Q35), cleft lip without cleft palate (Q36) and cleft lip with cleft palate (Q37), and the later two categories were merged into one for further analysis.

\section{Exposure assessment}

It has been well documented that the development of the lip and palate entails a complex series of events that happen between the 4th and 12th week of gestation [1, 6], we thus chose the first trimester of pregnancy as the susceptibility window for the collection of air pollutants data.

The pollution data were obtained from Hunan Environmental Monitoring Center. We included 15 air pollution monitoring stations in the study, with 10 from Changsha, 3 from Xiangtan, and 2 from Zhuzhou, respectively. The last 5 monitoring stations were included because they are in close vicinity of Changsha, and thus could be used to estimate the exposure levels of cases and controls who lived nearby (Fig. 1). All of these 15 monitoring stations are national air-quality monitoring stations. The installation of these stations and their collection of air pollutants strictly follow the national regulations. Daily 24-h mean concentrations of $\mathrm{CO}, \mathrm{NO}_{2}, \mathrm{SO}_{2}, \mathrm{PM}_{2.5}$, and $\mathrm{PM}_{10}$, and 8-h maximum concentration of ozone during the period of 2015-2018 were collected to satisfy the requirements of our analysis.

Individual daily exposure levels to air pollutants during the first trimester of pregnancy were predicted using the nearest monitoring station approach in regard of

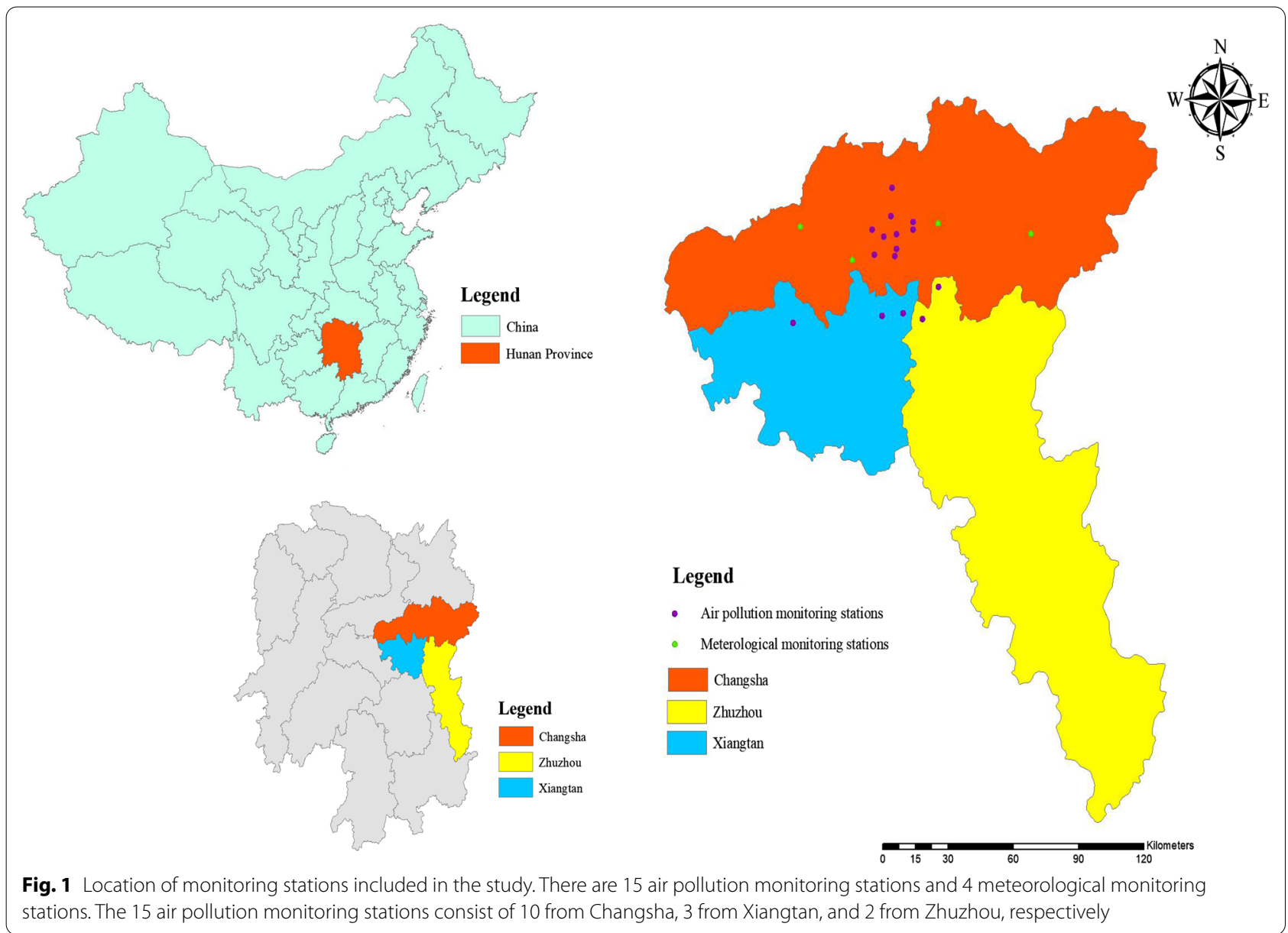


maternal residence. Briefly, we geocoded the residential address of each participating mother during early pregnancy and the locations of monitoring stations into longitude and latitude by using Baidu Maps (https://map. baidu.com), and calculated the distance between monitoring stations and each residential address using the software ARCGIS (version 10.3). Air pollutants data from the nearest monitoring station during the susceptibility window was then linked to each participating mother as the estimates of individual exposure levels. Monthly average values of $\mathrm{CO}, \mathrm{NO}_{2}, \mathrm{SO}_{2}, \mathrm{O}_{3}, \mathrm{PM}_{2.5}$, and $\mathrm{PM}_{10}$ were calculated for each subject.

To control for potential confounding by weather conditions, data on daily mean temperature and mean relative humidity of Changsha during the same study period from 4 local meteorological factors monitoring stations were averaged and used to represent the individual exposure levels during early pregnancy.

\section{Statistic analysis}

We assessed the association between monthly average exposure levels of gaseous air pollutants with orofacial clefts using multivariate logistic regression models. The whole analysis procedure in the study was divided into two stages. In the first stage, we constructed singlepollutant models for overall cases and subtypes. In the models of overall cases and CL/P, we adjusted for the following confounding factors according to the existing literatures and the significant differences in population characteristics between cases and controls: maternal age (classified as $<20$ years old, 20-24 years old, 25-29 years old and $\geq 30$ years old), maternal educational level (classified as middle school or below, high/technical school, and college or higher degree), gravidity (classified as 1 , 2,3 and $\geq 4$ ), infant sex (classified as female and male), plurality (classified as singleton and multiple birth), temperature and relative humidity. In the CPO model, we adjusted for same confounding factors except for sex because no significant sexual difference between $\mathrm{CPO}$ cases and controls was found. In the second stage, we further adjusted for $\mathrm{PM}_{2.5}$ and $\mathrm{PM}_{10}$ in separate twopollutant models. In order to examine if PM could be adjusted in the models, variance inflation factors (VIFs) were calculated, where a VIF $>10$ would suggest the existence of collinearity in the two-pollutant models, meaning that the confounding effect of $\mathrm{PM}_{2.5} / \mathrm{PM}_{10}$ could not be simultaneously adjusted. In contrast; a VIF $\leq 10$ would indicate no significant collinearity, so the effects of gaseous air pollutants could be considered as independent. ORs, along with their $95 \%$ confidence intervals (CIs), were used to present the effects of per interquartile range (IQR) increase in $\mathrm{CO}, \mathrm{NO}_{2}, \mathrm{SO}_{2}$ and $\mathrm{O}_{3}$, separately.
Moreover, considering that cases with multiple congenital anomalies might have more complex causes and a different etiology, which possibly bias our findings [22, 23], the two analysis stages which only included isolated orofacial cleft cases were conducted as a sensitivity analysis to test the stability of the results in the base case analysis.

All analyses were performed with the use of SAS (SAS Institute, Inc., Cary, North Carolina) and R (version 4.0.0; R Development Core Team), and a two tailed $P$ value less than 0.05 was considered statistically significant.

\section{Results}

\section{Descriptive statistics}

A total of 446 cases of orofacial clefts and 4460 controls were included in the current analysis. Compared to controls, cases had a higher ratio of mothers with younger age, lower educational levels and a history of multiple gravidity. Besides, difference in gender structure between $\mathrm{CL} / \mathrm{P}$ cases and controls was obvious, with higher ratio of male in cases. No significant difference in the season of conception was observed. Detailed characteristics of the subjects are summarized in Table 1. Additionally, the median ( 25 percentile to 75 percentile) distance between maternal residences during early pregnancy and the nearest monitoring station was $4.14(2.56-10.61) \mathrm{km}$.

The distribution of daily average air pollutant concentrations and meteorological factors in Changsha varied greatly during the study period, with a median (25th to 75th percentile range) concentration of 0.85 $(0.71-1.04) \mathrm{mg} / \mathrm{m}^{3}$ for CO, $31.30(23.20-44.70) \mu \mathrm{g} / \mathrm{m}^{3}$ for $\mathrm{NO}_{2}, 12.60(9.00-17.00) \mu \mathrm{g} / \mathrm{m}^{3}$ for $\mathrm{SO}_{2}, 84.55(54.55-$ 117.50) $\mu \mathrm{g} / \mathrm{m}^{3}$ for $\mathrm{O}_{3}, 44.20(28.50-67.00) \mu \mathrm{g} / \mathrm{m}^{3}$ for $\mathrm{PM}_{2.5}, 66.50(46.22-96.40) \mu \mathrm{g} / \mathrm{m}^{3}$ for $\mathrm{PM}_{10}, 18.68(10.45-$ $25.18){ }^{\circ} \mathrm{C}$ for temperature and $82.00(72.00-91.50) \%$ for relative humidity, respectively (Table 2 ). The results of correlation analysis of the air pollutants are presented in Additional file 1: Table S1, showing that all air pollutants were significantly associated with one another $(P<0.001)$, with Spearman correlation coefficients ranging from -0.08 to 0.91 .

\section{Associations between gaseous air pollutants and orofacial clefts}

Table 3 shows the aORs and corresponding 95\% confidence intervals (CIs) for the risk of orofacial clefts in relation to $\mathrm{CO}, \mathrm{NO}_{2}, \mathrm{SO}_{2}$ and $\mathrm{O}_{3}$ exposure during the first trimester of pregnancy. Elevated risks of overall cases for an IQR increase in $\mathrm{CO}, \mathrm{NO}_{2}$ and $\mathrm{SO}_{2}$ were found in all months of the first trimester of pregnancy, with aORs ranging from 1.35 to 1.42 for $\mathrm{CO}$, from 1.37 to 1.58 for $\mathrm{NO}_{2}$, and from 1.21 to 1.31 for $\mathrm{SO}_{2}$, respectively. By contrast, monthly $\mathrm{O}_{3}$ exposure showed nonsignificant effects 
Table 1 Characteristics of cases and controls from Changsha included in the study, 2015-2018

\begin{tabular}{|c|c|c|c|c|c|c|c|}
\hline \multirow[t]{2}{*}{ Characteristics } & \multicolumn{2}{|c|}{ Controls $(n=4460)$} & \multicolumn{2}{|c|}{ Overall Cases $(n=446)$} & \multirow[t]{2}{*}{$P$ value $^{a}$} & \multicolumn{2}{|c|}{$\begin{array}{l}\text { Cleft palate only } \\
(n=75)\end{array}$} \\
\hline & $N$ & (\%) & $\mathbf{N}$ & (\%) & & $\mathbf{N}$ & $(\%)$ \\
\hline Maternal age (years) & & & & & $<0.0001$ & & \\
\hline$<20$ & 14 & 0.31 & 5 & 1.12 & & 0 & 0.00 \\
\hline $20-24$ & 363 & 8.14 & 68 & 15.25 & & 12 & 16.00 \\
\hline $25-29$ & 1982 & 44.44 & 189 & 42.38 & & 33 & 44.00 \\
\hline$\geq 30$ & 2101 & 47.11 & 184 & 41.26 & & 30 & 40.00 \\
\hline Maternal education & & & & & $<0.0001$ & & \\
\hline Middle school or below & 0 & 0.00 & 60 & 13.45 & & 10 & 13.33 \\
\hline High/technical school & 1392 & 31.21 & 128 & 28.70 & & 18 & 24.00 \\
\hline College or higher degree & 3068 & 68.79 & 258 & 57.85 & & 47 & 62.67 \\
\hline Gravidity & & & & & $<0.0001$ & & \\
\hline 1 & 1559 & 34.96 & 106 & 23.77 & & 21 & 28.00 \\
\hline 2 & 1315 & 29.48 & 131 & 29.37 & & 24 & 32.00 \\
\hline 3 & 799 & 17.91 & 101 & 22.65 & & 12 & 16.00 \\
\hline$\geq 4$ & 787 & 17.65 & 108 & 24.22 & & 18 & 24.00 \\
\hline Season of conception & & & & & 0.0742 & & \\
\hline Warm & 2615 & 58.63 & 242 & 54.26 & & 44 & 58.67 \\
\hline Cold & 1845 & 41.37 & 204 & 45.74 & & 31 & 41.33 \\
\hline Plurality & & & & & 0.1397 & & \\
\hline Singleton & 4252 & 93.95 & 432 & 96.86 & & 74 & 98.67 \\
\hline Multiple birth & 208 & 6.05 & 14 & 3.14 & & 1 & 1.33 \\
\hline Infant sex ${ }^{b}$ & & & & & 0.0004 & & \\
\hline Female & 2135 & 47.62 & 174 & 39.01 & & 36 & 48.00 \\
\hline Male & 2325 & 52.38 & 272 & 60.99 & & 39 & 52.00 \\
\hline
\end{tabular}

${ }^{a}$ Chi-square test for equal distribution of categorical variables between overall cases and controls

${ }^{\mathrm{b}}$ There is no significant sexual difference between CPO cases and controls

Table 2 Distribution of daily average air pollutant concentration and meteorological factors during 2015-2018 in Changsha, China

\begin{tabular}{lccccrrr}
\hline & Min & 25 percentile & Median & 75 percentile & Max & IQR & Mean \\
\hline $\mathrm{CO}\left(\mathrm{mg} / \mathrm{m}^{3}\right)$ & 0.41 & 0.71 & 0.85 & 1.04 & 2.17 & 0.33 & 0.90 \\
$\mathrm{SO}_{2}\left(\mu \mathrm{g} / \mathrm{m}^{3}\right)$ & 3.80 & 9.00 & 12.60 & 17.00 & 71.20 & 8.00 & 14.04 \\
$\mathrm{NO}_{2}\left(\mu \mathrm{g} / \mathrm{m}^{3}\right)$ & 9.90 & 23.20 & 31.30 & 44.70 & 107.00 & 21.50 & 35.56 \\
$\mathrm{O}_{3}\left(\mu \mathrm{g} / \mathrm{m}^{3}\right)$ & 7.70 & 54.55 & 84.55 & 117.50 & 228.20 & 62.95 & 88.51 \\
$\mathrm{PM}_{2.5}\left(\mu \mathrm{g} / \mathrm{m}^{3}\right)$ & 3.20 & 28.50 & 44.20 & 67.00 & 278.90 & 38.50 & 52.26 \\
$\mathrm{PM}_{10}\left(\mu \mathrm{g} / \mathrm{m}^{3}\right)$ & 5.40 & 46.22 & 66.50 & 96.40 & 411.30 & 50.18 & 75.40 \\
Temperature $\left({ }^{\circ} \mathrm{C}\right)$ & -1.98 & 10.45 & 18.68 & 25.18 & 33.03 & 14.73 & 18.04 \\
Relative humidity $(\%)$ & 40.25 & 72.00 & 82.00 & 91.50 & 99.25 & 19.50 & 80.61 \\
\hline
\end{tabular}

on overall cases. In the subgroup analysis, similar association patterns for the outcome CL/P were observed. However, the risk of $\mathrm{CPO}$ only increased with increasing $\mathrm{NO}_{2}$ exposure levels in the first trimester of pregnancy, with aORs ranging from 1.60 to 1.66 .

Table 4 presents the associations between outcomes and four gaseous air pollutants after adjusting for $\mathrm{PM}_{2.5}$.
Most of the significant effects were sustained and even enhanced, with aORs ranging from 1.46 to 1.91 for $\mathrm{CO}$, 1.60 to 2.11 for $\mathrm{NO}_{2}, 1.34$ to 2.10 for $\mathrm{SO}_{2}$, respectively. Enhanced effects on orofacial clefts were also observed for $\mathrm{CO}, \mathrm{NO}_{2}$ and $\mathrm{SO}_{2}$ after adjusting for $\mathrm{PM}_{10}$ (Table 5). All VIFs in the two-pollutant models were less than 2 
Table 3 Adjusted odds ratios (95\% confidence intervals) for orofacial clefts during the first trimester of pregnancy

\begin{tabular}{|c|c|c|c|}
\hline \multirow[t]{2}{*}{ Air pollutant/time scale } & $\begin{array}{l}\text { Overall cases } \\
(n=446)\end{array}$ & $\begin{array}{l}\text { Cleft lip with or without cleft palate } \\
(n=371)\end{array}$ & $\begin{array}{l}\text { Cleft palate only } \\
(n=75)\end{array}$ \\
\hline & & & \\
\hline \multicolumn{4}{|l|}{ Per IQR increase in CO } \\
\hline 1st month & $1.37(1.19,1.59)$ & $1.44(1.23,1.69)$ & $1.24(0.84,1.82)$ \\
\hline 2nd month & $1.35(1.17,1.57)$ & $1.39(1.19,1.63)$ & $1.19(0.81,1.76)$ \\
\hline 3rd month & $1.42(1.23,1.64)$ & $1.48(1.26,1.73)$ & $1.16(0.79,1.68)$ \\
\hline \multicolumn{4}{|l|}{ Per IQR increase in $\mathrm{NO}_{2}$} \\
\hline 1st month & $1.58(1.36,1.83)$ & $1.606(1.36,1.89)$ & $1.63(1.12,2.37)$ \\
\hline 2nd month & $1.52(1.31,1.77)$ & $1.48(1.25,1.75)$ & $1.66(1.15,2.39)$ \\
\hline 3rd month & $1.37(1.18,1.59)$ & $1.35(1.14,1.59)$ & $1.60(1.12,2.29)$ \\
\hline \multicolumn{4}{|l|}{ Per IQR increase in $\mathrm{SO}_{2}$} \\
\hline 1st month & $1.21(1.03,1.41)$ & $1.22(1.04,1.44)$ & $1.20(0.77,1.85)$ \\
\hline 2nd month & $1.31(1.12,1.55)$ & $1.35(1.14,1.61)$ & $1.16(0.73,1.84)$ \\
\hline 3rd month & $1.30(1.12,1.51)$ & $1.34(1.14,1.58)$ & $0.99(0.66,1.47)$ \\
\hline \multicolumn{4}{|l|}{ Per IQR increase in $\mathrm{O}_{3}$} \\
\hline 1st month & $0.85(0.70,1.03)$ & $0.84(0.68,1.03)$ & $0.91(0.56,1.46)$ \\
\hline 2nd month & $0.91(0.95,1.10)$ & $0.90(0.73,1.11)$ & $0.86(0.54,1.37)$ \\
\hline 3rd month & $1.04(0.86,1.26)$ & $1.08(0.87,1.34)$ & $0.89(0.56,1.41)$ \\
\hline
\end{tabular}

In the models of overall cases and CL/P, adjusted covariates including maternal age, maternal educational level, gravidity, infant sex, plurality, temperature and relative humidity. In the model of CPO, only maternal age, maternal educational level, gravidity, plurality, temperature and relative humidity were adjusted

aOR, adjusted odds ratio; $\mathrm{Cl}$, confidence interval

Table 4 Adjusted odds ratios (95\% confidence intervals) for orofacial clefts after additionally adjusting for $\mathrm{PM}_{2.5}$ during the first trimester of pregnancy

\begin{tabular}{|c|c|c|c|}
\hline \multirow[t]{2}{*}{ Air pollutant/time scale } & \multirow{2}{*}{$\begin{array}{l}\text { Overall cases } \\
(\mathrm{n}=446) \\
\text { aOR }(95 \% \mathrm{Cl})\end{array}$} & \multirow{2}{*}{$\begin{array}{l}\text { Cleft lip with or without cleft palate } \\
(\mathrm{n}=371) \\
\text { aOR }(95 \% \mathrm{Cl})\end{array}$} & \multirow{2}{*}{$\begin{array}{l}\text { Cleft palate only } \\
(\mathrm{n}=75) \\
\text { aOR }(95 \% \mathrm{Cl})\end{array}$} \\
\hline & & & \\
\hline \multicolumn{4}{|l|}{ Per IQR increase in CO } \\
\hline 1st month & $1.46(1.20,1.77)$ & $1.61(1.30,2.00)$ & $0.95(0.56,1.61)$ \\
\hline 2nd month & $1.48(1.22,1.80)$ & $1.57(1.28,1.94)$ & $1.06(0.62,1.80)$ \\
\hline 3rd month & $1.79(1.48,2.17)$ & $1.91(1.55,2.36)$ & $1.14(0.66,1.96)$ \\
\hline \multicolumn{4}{|l|}{ Per IQR increase in $\mathrm{NO}_{2}$} \\
\hline 1st month & $1.92(156,2.36)$ & $2.00(1.59,2.51)$ & $1.88(0.94,2.69)$ \\
\hline 2nd month & $1.84(1.50,2.26)$ & $1.76(1.41,2.21)$ & $2.05(1.22,3.44)$ \\
\hline 3rd month & $1.65(1.36,2.01)$ & $1.60(1.29,1.99)$ & $2.11(1.28,3.47)$ \\
\hline \multicolumn{4}{|l|}{ Per IQR increase in $\mathrm{SO}_{2}$} \\
\hline 1st month & $1.46(0.91,2.33)$ & $1.18(0.98,1.42)$ & $1.00(0.60,1.64)$ \\
\hline 2nd month & $2.00(1.25,3.19)$ & $1.34(1.12,1.62)$ & $1.07(0.65,1.76)$ \\
\hline 3rd month & $2.10(1.37,3.21)$ & $1.36(1.15,1.62)$ & $0.95(0.63,1.45)$ \\
\hline \multicolumn{4}{|l|}{ Per IQR increase in $\mathrm{O}_{3}$} \\
\hline 1st month & $0.94(0.74,1.18)$ & $0.91(0.70,1.17)$ & $1.23(0.70,2.17)$ \\
\hline 2nd month & $0.99(0.78,1.26)$ & $0.97(0.75,1.26)$ & $1.00(0.57,1.78)$ \\
\hline 3rd month & $1.12(0.88,1.42)$ & $1.18(0.91,1.54)$ & $0.94(0.53,1.68)$ \\
\hline
\end{tabular}

In the models of overall cases and CL/P, adjusted covariates including maternal age, maternal educational level, gravidity, infant sex, plurality, temperature, relative humidity and $\mathrm{PM}_{2.5}$. In the model of $\mathrm{CPO}$, only maternal age, maternal educational level, gravidity, plurality, temperature, relative humidity and PM 2.5 were adjusted $\mathrm{aOR}$, adjusted odds ratio; $\mathrm{Cl}$, confidence interval 
Table 5 Adjusted odds ratios (95\% confidence intervals) for orofacial clefts after additionally adjusting for $\mathrm{PM}_{10}$ during the first trimester of pregnancy

\begin{tabular}{|c|c|c|c|}
\hline \multirow[t]{2}{*}{ Air pollutant/time scale } & $\begin{array}{l}\text { Overall cases } \\
(n=446)\end{array}$ & $\begin{array}{l}\text { Cleft lip with or without cleft palate } \\
(n=371)\end{array}$ & $\begin{array}{l}\text { Cleft palate only } \\
(n=75)\end{array}$ \\
\hline & aOR $(95 \% \mathrm{Cl})$ & aOR $(95 \% \mathrm{Cl})$ & aOR $(95 \% \mathrm{Cl})$ \\
\hline \multicolumn{4}{|l|}{ Per IQR increase in CO } \\
\hline 1st month & $1.41(1.20,1.67)$ & $1.49(1.25,1.78)$ & $1.23(0.80,1.91)$ \\
\hline 2nd month & $1.36(1.16,1.60)$ & $1.40(1.18,1.67)$ & $1.16(0.74,1.81)$ \\
\hline 3rd month & $1.49(1.27,1.75)$ & $1.55(1.30,1.84)$ & $1.17(0.76,1.81)$ \\
\hline \multicolumn{4}{|l|}{ Per IQR increase in $\mathrm{NO}_{2}$} \\
\hline 1st month & $1.78(1.49,2.12)$ & $1.79(1.48,2.18)$ & $1.88(1.19,2.96)$ \\
\hline 2nd month & $1.66(1.39,2.00)$ & $1.59(1.30,1.94)$ & $1.98(1.25,3.14)$ \\
\hline 3rd month & $1.50(1.26,1.79)$ & $1.44(1.18,1.75)$ & $1.98(1.28,3.07)$ \\
\hline \multicolumn{4}{|l|}{ Per IQR increase in $\mathrm{SO}_{2}$} \\
\hline 1st month & $1.20(1.01,1.44)$ & $1.21(1.00,1.46)$ & $1.17(0.71,1.94)$ \\
\hline 2nd month & $1.31(1.09,1.58)$ & $1.35(1.11,1.65)$ & $1.09(0.63,1.88)$ \\
\hline 3rd month & $1.35(1.14,1.60)$ & $1.39(1.16,1.67)$ & $0.96(0.60,1.54)$ \\
\hline \multicolumn{4}{|l|}{ Per IQR increase in $\mathrm{O}_{3}$} \\
\hline 1st month & $0.87(0.71,1.06)$ & $0.86(0.69,1.06)$ & $0.93(0.57,1.52)$ \\
\hline 2nd month & $0.94(0.78,1.14)$ & $0.94(0.76,1.16)$ & $0.89(0.55,1.43)$ \\
\hline 3rd month & $1.06(0.87,1.30)$ & $1.11(0.89,1.39)$ & $0.89(0.55,1.43)$ \\
\hline
\end{tabular}

In the models of overall cases and $\mathrm{CL} / \mathrm{P}$, adjusted covariates including maternal age, maternal educational level, gravidity, infant sex, plurality, temperature, relative humidity and $\mathrm{PM}_{10}$. In the model of $\mathrm{CPO}$, only maternal age, maternal educational level, gravidity, plurality, temperature, relative humidity and $\mathrm{PM}_{10}$ were adjusted

$\mathrm{aOR}$, adjusted odds ratio; $\mathrm{Cl}$, confidence interval

(data not shown), suggesting there is no evidence for significant collinearity.

In the sensitivity analysis, the associations between gaseous air pollutants exposure and the risk of orofacial clefts remained when only isolate cases diagnosed without anomalies in other systems $(\mathrm{n}=379)$ were included (Additional file 1: Tables S2-S4).

\section{Discussion}

In this study, we investigated the associations between gaseous air pollutants exposure during the first trimester of pregnancy and the risk of orofacial clefts in Changsha, China using a case-control study design. We found positive effects of $\mathrm{CO}, \mathrm{NO}_{2}$ and $\mathrm{SO}_{2}$ exposure on orofacial clefts independent of particulate matter $\left(\mathrm{PM}_{2.5}\right.$ and $\mathrm{PM}_{10}$ ). While no significant association between $\mathrm{O}_{3}$ and orofacial clefts was found.

In the single pollutant analysis of $\mathrm{CO}$, the risk of $\mathrm{CL} / \mathrm{P}$ increased by $39-48 \%$ with a IQR increase in CO during the first trimester of pregnancy. The association was of comparable magnitude with a prospective cohort study including 133 cases of orofacial clefts from Wuhan, China, in which Zhao et al. observed that per $100 \mu \mathrm{g} / \mathrm{m}^{3}$ increase in $\mathrm{CO}$ increased the risk of $\mathrm{CL} / \mathrm{P}$ in the second and the third month of pregnancy, with aORs of 1.31 (95\% CI 1.14, 1.51) and 1.17 (95\% CI 1.03, 1.33), respectively [15]. In contrast, another cohort study performed by Zhu et al. in the U.S. found significant effect of $\mathrm{CO}$ exposure on $\mathrm{CPO}(\mathrm{aOR}=2.74,95 \% \mathrm{CI} 1.62,4.62)$, but not on $\mathrm{CL} / \mathrm{P}$ during gestational weeks 3-8 [11]. Some other studies from different countries or regions also assessed the effect of $\mathrm{CO}$ on orofacial clefts, while observed insignificant $[6,24,25]$ or reverse associations [26, 27].

In the single pollutant analysis of $\mathrm{NO}_{2}$, we observed increases of $35-61 \%$ in the risk of $\mathrm{CL} / \mathrm{P}$, as well as increases of $60-66 \%$ in the risk of CPO per IQR increase in $\mathrm{NO}_{2}$ in all months of the first trimester of pregnancy. Our estimates supported the results from the studies performed by Zhu et al. in the U.S. [11] and Wang et al. in China [18], which reported an aOR of 3.64 (95\% CI 1.73, 7.66) for CPO per IQR increase during weeks 3-8 of pregnancy and a RR of 1.19 (95\% CI 1.03, 1.36) for cleft palate per $10 \mu \mathrm{g} / \mathrm{m}^{3}$ increase during the first trimester of pregnancy, respectively. No other previous studies that estimated the effect of $\mathrm{NO}_{2}$ found significant results [18, $26,28]$.

In the single pollutant analysis of $\mathrm{SO}_{2}$, we observed consistent and positive effects on $\mathrm{CL} / \mathrm{P}$ during the period studied, with aORs ranging from 1.22 to 1.35 . Similarly, in a case-control study with 145 cases from Australia, Hansen et al. found per IQR increase in $\mathrm{SO}_{2}$ exposure during weeks 3-8 of pregnancy was associated with elevated risk of $\mathrm{CL} / \mathrm{P}(\mathrm{aOR}=1.27,95 \% \mathrm{CI} 1.01,1.62)$ [24]. Besides, Marshall et al. in a study from New Jersey also 
provided evidence for the association between $\mathrm{CL} / \mathrm{P}$ and $\mathrm{SO}_{2}$ at the highest exposure level $(\mathrm{aOR}=1.6,95 \% \mathrm{CI} 1.1$, 2.2) [26]. However, another study performed by Liu et al. in Liaoning, China reported no significant effects [17].

$\mathrm{O}_{3}$ is a secondary pollutant formed through reactions of volatile organic compounds and $\mathrm{NO}_{2}$ in the presence of sunlight [29], and its association with orofacial clefts has been investigated in a larger number of epidemiological studies compared to other gaseous air pollutants. However, only a few of them found positive results. For instance, a case-control study including 653 cases from Taiwan, China reported the risk of $\mathrm{CL} / \mathrm{P}$ was increased in relation to $\mathrm{O}_{3}$ levels in the first $(\mathrm{aOR}=1.20,95 \% \mathrm{CI} 1.02$, $1.39)$ and the second month of pregnancy $(\mathrm{aOR}=1.25$, 95\% CI 1.03, 1.52) [6], Another cohort study performed by Zhao et al.in Wuhan, China announced significant associations for $\mathrm{CPO}$ in the second and the third month of pregnancy, with aORs of 1.21 (95\% CI 1.03, 1.42) and 1.18 (95\% CI 1.02, 1.37), respectively [15]. Unfortunately, we failed to detect a positive effect of $\mathrm{O}_{3}$ on $\mathrm{CL} / \mathrm{P}$ or $\mathrm{CPO}$ in Changsha, China in this study, as did most of the previous studies $[10,12,18]$.

In our study area, the concentrations of air pollutants were higher than in areas covered by most of the previous studies, especially those from developed countries. As a result, it is reasonable to partially attribute our obvious findings to the differences in the level and the range of air pollutants across studies. Other factors, such as differences in the coverage of region and time period, statistical method used, covariates adjusted for, and characteristics of the subjects across studies may also result in mixed results [15]. Besides, we noticed that the effects of $\mathrm{NO}_{2}$ on $\mathrm{CL} / \mathrm{P}$ were stronger than those of $\mathrm{CO}$ and $\mathrm{SO}_{2}$. One possible reason is that $\mathrm{NO}_{2}$ has stronger toxic effect on the development of $\mathrm{CL} / \mathrm{P}$, another is that the population studied were more sensitive to $\mathrm{NO}_{2}$ exposure. More animal studies comparing the toxic effects of different air pollutants are warranted to address this hypothesis. What is more, only $\mathrm{NO}_{2}$ exposure was observed to be associated with increased risk of CPO. Although the embryological pathogens of $\mathrm{CL} / \mathrm{P}$ and $\mathrm{CPO}$ were different [1], the null associations between other air pollutants and the CPO subgroup may also result from the lack of sufficient statistical power with small case numbers.

The question of whether the observed associations for gaseous air pollutants were independent of particulate matter is important for health-risk assessment. Based on our analysis, the magnitudes of the effects of $\mathrm{CO}, \mathrm{NO}_{2}$ and $\mathrm{SO}_{2}$ remained significant and even increased in the two-pollutant models, and the VIFs were all $<2$, which provides evidence for independent effects of the three pollutants. Two previous studies have built co-pollutants models to adjust for coexistent pollutants for $\mathrm{O}_{3}$ and
$\mathrm{PM}_{10}$, respectively [6,30]. Although both of the studies observed increased effects of the air pollutants studied compared to single-pollutant models, which is in lines with our findings, neither provided plausible explanations for the interesting patterns. We hypothesize that both particulate matter and gaseous pollutants may be involved in the same pathways contributing to the development of orofacial clefts, and thus generate competitive relationships. As a result, the effects of gaseous pollutants were exacerbated after we controlled for PM in the models. However, more efforts are needed to test if the observed patterns are real.

The biological mechanism underlying the associations between gaseous air pollutants and orofacial clefts remains unclear. Data from animal studies provided several explanations for the potential teratogenicity of air pollutants. For instance, exposure to $\mathrm{CO}$ could lead to hypoxia [31, 32], reaction with hem-containing proteins $[31,33]$, and a reduction in metabolization of xenobiotics $[27,34]$, these responses can further trigger the fetotoxic effects even at a low concentration level [35]. Exposure to $\mathrm{NO}_{2}$ might cause the development of orofacial clefts by inducing the generation of inflammatory response or epigenetic changes, such as DNA methylation [36-38]. With respect to $\mathrm{SO}_{2}$, some studies suggest it could cause oxidative damage and induce multiple organ malformations in mice [39]. Although we did not observe significant effect for $\mathrm{O}_{3}$, there is evidence from an animal study indicating $\mathrm{O}_{3}$ exposure could act as a toxin to influence the fetal development in rats through hemodynamic, anoxic events, oxidative stress, and toxicity to certain cell populations [5]. More studies are needed to address the knowledge gaps.

To the best of our knowledge, the present study is one of the few studies to investigate associations between gaseous air pollutants exposure during the first trimester of pregnancy and risk of orofacial clefts in China. Our study would be in a better position to investigate this issue for three major reasons. We used the latest diagnosed cases and air pollution data from an area with high incidence of birth defect and higher levels of air pollution compared to developed countries. The results will be relevant for public health in areas with similar air pollution concentrations. We constructed two-pollutant models, and calculated VIFs to distinguish the independent effects of gaseous air pollutants, which made our results more persuasive. We included stillbirths, dead fetuses and liveborn infants with orofacial clefts in the study area, which reduced potential selective bias compared to those studies which included live-born cases only.

Limitations in our study should be acknowledged. As in most previous researches, misclassification bias in the exposure estimation for individuals based on the 
nearest monitoring station approach was inevitable. However, the misclassification has been proven to be random and make the results bias towards the null [40]. We have no data on certain potential confounding factors, such as maternal occupational exposures, maternal nutrient, alcohol use and smoking during early pregnancy. Although the prevalence of smoking among Chinese women is quite low overall [41], and there is evidence from the U.S. showing that the risk of air pollutants on adverse outcomes changed by less than $5 \%$ after adjusting for occupation, income, maternal smoking and environmental tobacco smoke, and alcohol drinking [42], we cannot conclude that the absence of such information would not greatly change our results because the characteristics of populations in the current study may differ from those in developed countries (i.e. high environmental tobacco smoke prevalence among Chinese women[43]). Because of all the limitations mentioned above, the findings should be interpreted cautiously before extension to other populations and researches.

\section{Conclusion}

Our study suggested that maternal exposure to $\mathrm{CO}, \mathrm{NO}_{2}$, and $\mathrm{SO}_{2}$ during the first trimester of pregnancy were associated with increased risk of orofacial clefts, and the effects of the three gaseous air pollutants were potentially independent of $\mathrm{PM}_{2.5}$ and $\mathrm{PM}_{10}$. Our findings highlights the importance of addressing the effects of gaseous air pollutants on orofacial clefts in Changsha, China.

\section{Abbreviations}

CL/P: Cleft lip with or without cleft palate; CPO: Cleft palate only; VIF: Variance inflation factor; PM: Particulate matter; IQR: Interquartile range; aOR: Adjusted odds ratio; $\mathrm{Cl}$ : Confidence interval.

\section{Supplementary Information}

The online version contains supplementary material available at https://doi. org/10.1186/s12903-021-01876-7.

Additional file 1. Supplementary materials.

\section{Authors' contributions}

WJ: Conceptualization, Methodology, Writing-Original Draft, Formal analysis WX: Writing-Original Draft, Formal analysis, Software, Visualization BN: Supervision, Funding acquisition HZ: Validation, Software ZL: Resources, Data curation, Funding acquisition XL: Conceptualization, Methodology, Writing—Review \& Editing, Funding acquisition. All authors have read and agreed to the published version of the manuscript.

\section{Funding}

The study is funded by Major Scientific and Technological Projects for Collaborative Prevention and Control of Birth Defects in Hunan Province

(2019SK1012), Major Research and Development Projects in Hunan Province
(2018SK2060) and Scientific and Technological Department Projects in Hunan Province (2017SK50802).

\section{Availability of data and materials}

The datasets generated and/or analysed during the current study are not publicly available due ethical reason but are available from the corresponding author on reasonable request.

\section{Declarations}

\section{Ethics approval and consent to participate}

The study was reviewed and approved by the Medical Ethics Committee of Maternal and Child Health Care Hospital of Hunan Province. Written informed consent was not required.

\section{Consent for publication}

Not applicable.

\section{Competing interests}

The authors declare that they have no competing interests.

Received: 2 August 2021 Accepted: 28 September 2021

Published online: 15 October 2021

\section{References}

1. Mossey PA, Little J, Munger RG, Dixon MJ, Shaw WC. Cleft lip and palate. Lancet. 2009:374(9703):1773-85.

2. Christensen $\mathrm{K}$, Juel $\mathrm{K}$, Herskind AM, Murray JC. Long term follow up study of survival associated with cleft lip and palate at birth. BMJ. 2004;328(7453):1405.

3. Worley ML, Patel KG, Kilpatrick LA. Cleft lip and palate. Clin Perinatol. 2018;45(4):661-78.

4. Singh J, Aggison LJ, Moore-Cheatum L. Teratogenicity and developmental toxicity of carbon monoxide in protein-deficient mice. Teratology. 1993;48(2):149-59.

5. Kavlock RJ, Meyer E, Grabowski CT. Studies on the developmental toxicity of ozone: postnatal effects. Toxicol Lett. 1980;5(1):3-9.

6. Hwang B, Jouni JKJ. Ozone and other air pollutants and the risk of oral clefts. Environ Health Perspect. 2008;116(10):1411-5.

7. Tanner JP, Salemi JL, Stuart AL, Yu H, Jordan MM, DuClos C, Cavicchia P, Correia JA, Watkins SM, Kirby RS. Associations between exposure to ambient benzene and PM2.5 during pregnancy and the risk of selected birth defects in offspring. Environ Res. 2015;142:345-53.

8. Zhou Y, Gilboa SM, Herdt ML, Lupo PJ, Flanders WD, Liu Y, Shin M, Canfield MA, Kirby RS. Maternal exposure to ozone and PM(2.5) and the prevalence of orofacial clefts in four U.S. states. Environ Res. 2017;153:35-40.

9. Girguis MS, Strickland MJ, Hu X, Liu Y, Bartell SM, Vieira VM. Maternal exposure to traffic-related air pollution and birth defects in Massachusetts. Environ Res. 2016;146:1-9.

10. Zhou Y, Gilboa SM, Herdt ML, Lupo PJ, Flanders WD, Liu Y, Shin M, Canfield MA, Kirby RS. Maternal exposure to ozone and PM2.5 and the prevalence of orofacial clefts in four U.S. states. Environ Res. 2017;153:35-40.

11. Zhu Y, Zhang C, Liu D, Grantz KL, Wallace M, Mendola P. Maternal ambient air pollution exposure preconception and during early gestation and offspring congenital orofacial defects. Environ Res. 2015;140:714-20.

12. Pedersen M, Garne E, Hansen-Nord N, Hjortebjerg D, Ketzel M, RaaschouNielsen O, Nybo Andersen A, Sørensen M. Exposure to air pollution and noise from road traffic and risk of congenital anomalies in the Danish National Birth Cohort. Environ Res. 2017;159:39-45.

13. Farhi A, Boyko V, Almagor J, Benenson I, Segre E, Rudich Y, Stern E, LernerGeva L. The possible association between exposure to air pollution and the risk for congenital malformations. Environ Res. 2014;135:173-80.

14. Ren L, Yang W, Bai Z. Characteristics of major air pollutants in China. Adv Exp Med Biol. 2017;1017:7-26.

15. Zhao J, Zhang B, Yang S, Mei H, Qian Z, Liang S, Zhang Y, Hu K, Tan Y, Xian $\mathrm{H}$, et al. Maternal exposure to ambient air pollutant and risk of oral clefts in Wuhan, China. Environ Pollut. 2018;238:624-30. 
16. Wang $L$, Xiang $X$, Mi B, Song H, Dong M, Zhang S, Bi Y, Zhao Y, Li Q, Zhang $Q$, et al. Association between early prenatal exposure to ambient air pollution and birth defects: evidence from newborns in Xi'an, China. J Public Health-UK. 2019;41(3):494-501.

17. Liu F, Xing Z, Gong T, Zhang J, Huang Y, Li J, Liu S, Chen Y, Li L, Jiang C, et al. Maternal exposure to sulfur dioxide and the risk of oral clefts in Liaoning Province, China: a population-based case-control study. Environ Sci Pollut Res Int. 2021;28(29):39101-9.

18. Huang X, Chen J, Zeng D, Lin Z, Herbert C, Cottrell L, Liu L, Ash A, Wang B. The association between ambient air pollution and birth defects in five major ethnic groups in Liuzhou, China. BMC Pediatr. 2021;21(1):232.

19. Rohde RA, Muller RA. Air pollution in China: Mapping of concentrations and sources. PLoS ONE. 2015;10(8):e135749.

20. Xie D, Yang T, Liu Z, Wang H. Epidemiology of birth defects based on a birth defect surveillance system from 2005 to 2014 in Hunan Province, China. PLoS ONE. 2016;11(1):e147280.

21. Padula AM, Tager IB, Carmichael SL, Hammond SK, Yang W, Lurmann FW, Shaw GM. Traffic-related air pollution and selected birth defects in the San Joaquin Valley of California. Birth Defects Res A Clin Mol Teratol. 2013;97(11):730-5.

22. Agay-Shay K, Friger M, Linn S, Peled A, Amitai Y, Peretz C. Air pollution and congenital heart defects. Environ Res. 2013;124:28-34.

23. Nie Z, Yang B, Ou Y, Bloom MS, Han F, Qu Y, Nasca P, Matale R, Mai J, Wu $Y$, et al. Maternal residential greenness and congenital heart defects in infants: a large case-control study in Southern China. Environ Int. 2020;142(9):105859.

24. Hansen CA, Barnett AG, Jalaludin BB, Morgan GG. Ambient air pollution and birth defects in Brisbane, Australia. PLOS ONE. 2009;4(4):e5408.

25. Gilboa SM, Mendola P, Olshan AF, Langlois PH, Savitz DA, Loomis D, Herring AH, Fixler DE. Relation between ambient air quality and selected birth defects, seven county study, Texas, 1997-2000. Am J Epidemiol. 2005;162(3):238-52

26. Marshall EG, Harris G, Wartenberg D. Oral cleft defects and maternal exposure to ambient air pollutants in New Jersey. Birth Defects Res A. 2010;88(4):205-15.

27. Ritz B, Yu F, Fruin S, Chapa G, Shaw GM, Harris JA. Ambient air pollution and risk of birth defects in Southern California. Am J Epidemiol. 2002;155(1):17-25.

28. Schembari A, Nieuwenhuijsen MJ, Salvador J, de Nazelle A, Cirach M, Dadvand P, Beelen R, Hoek G, Basagaña X, Vrijheid M. Traffic-related air pollution and congenital anomalies in Barcelona. Environ Health Perspect. 2014;122(3):317-23

29. Zhang B, Zhao J, Yang R, Qian Z, Liang S, Bassig BA, Zhang Y, Hu K, Xu S, Dong $\mathrm{G}$, et al. Ozone and other air pollutants and the risk of congenital heart defects. Sci Rep. 2016;6:34852.

30. Liu F, Dai H, Gong T, Zhang J, Li J, Chen Z, Li L, Chen Y, Liu S, Jiang C, et al. Maternal preconception and first trimester exposure to PM10 and the risk of oral clefts in offspring: a population-based, case-control study. Occup Environ Med. 2020;77(10):721-7.

31. Aubard Y, Magne I. Carbon monoxide poisoning in pregnancy. BJOG. 2000;107(7):833-8.

32. Maisonet M, Correa A, Misra D, Jaakkola JJ. A review of the literature on the effects of ambient air pollution on fetal growth. Environ Res. 2004:95(1):106-15.

33. Gabrielli A, Layon AJ. Carbon monoxide intoxication during pregnancy: a case presentation and pathophysiologic discussion, with emphasis on molecular mechanisms. J Clin Anesth. 1995;7(1):82-7.

34. Garvey DJ, Longo LD. Chronic low level maternal carbon monoxide exposure and fetal growth and development. Biol Reprod. 1978;19(1):8-14.

35. Ernst A, Zibrak JD. Carbon monoxide poisoning. N Engl J Med. 1998:339(22):1603-8.

36. Nawrot TS, Adcock I. The detrimental health effects of traffic-related air pollution: a role for DNA methylation? Am J Respir Crit Care Med. 2009;179(7):523-4.

37. Serra-Juhé C, Cuscó I, Homs A, Flores R, Torán N, Pérez-Jurado LA. DNA methylation abnormalities in congenital heart disease. Epigenetics. 2015:10(2):167-77.

38. van den Hooven EH, de Kluizenaar Y, Pierik FH, Hofman A, van Ratingen SW, Zandveld PY, Lindemans J, Russcher H, Steegers EA, Miedema HM, et al. Chronic air pollution exposure during pregnancy and maternal and fetal C-reactive protein levels: the Generation R Study. Environ Health Perspect. 2012;120(5):746-51.

39. Meng Z. Oxidative damage of sulfur dioxide on various organs of mice: sulfur dioxide is a systemic oxidative damage agent. Inhal Toxicol. 2003;15(2):181-95.

40. Zeger SL, Thomas D, Dominici F, Samet JM, Schwartz J, Dockery D, Cohen A. Exposure measurement error in time-series studies of air pollution: concepts and consequences. Environ Health Perspect. 2000;108(5):419-26.

41. Li Q, Hsia J, Yang G. Prevalence of smoking in China in 2010. N Engl J Med. 2011;364(25):2469-70.

42. Ritz B, Wilhelm M, Hoggatt KJ, Ghosh JK. Ambient air pollution and preterm birth in the environment and pregnancy outcomes study at the University of California, Los Angeles. Am J Epidemiol. 2007;166(9):1045-52.

43. Vinceti M, Malagoli C, Malavolti M, Cherubini A, Maffeis G, Rodolfi R, Heck JE, Astolfi G, Calzolari E, Nicolini F. Does maternal exposure to benzene and PM 10 during pregnancy increase the risk of congenital anomalies? A population-based case-control study. Sci Total Environ. 2016:541:444-50.

\section{Publisher's Note}

Springer Nature remains neutral with regard to jurisdictional claims in published maps and institutional affiliations.
Ready to submit your research? Choose BMC and benefit from:

- fast, convenient online submission

- thorough peer review by experienced researchers in your field

- rapid publication on acceptance

- support for research data, including large and complex data types

- gold Open Access which fosters wider collaboration and increased citations

- maximum visibility for your research: over 100M website views per year

At BMC, research is always in progress.

Learn more biomedcentral.com/submissions 